\title{
PENGARUH HARGA DAN KUALITAS PRODUK TERHADAP KEPUTUSAN PEMBELIAN KONSUMEN PADA SHAMPO MEREK REJOICE PADA MASYARAKAT RANTAUPRAPAT
}

\author{
Elvina \\ Sekolah Tinggi Ilmu Ekonomi Labuhanbatu, Sumatera Utara - Indonesia \\ E-mail : elvinahrp19@gmail.com
}

\begin{abstract}
The purpose of this research is: 1) to know the influence of the price of the consumer purchasing decisions on shampoo products registered Rejoice on the community Rantauprapat, 2) to know the influence of product quality to the consumer purchasing decisions on shampoo products registered Rejoice on the community Rantauprapat. The hypothesis of this research are influential price variable significant for consumer purchasing decisions on shampoo products registered Rejoice on the community Rantauprapat, and product quality variables affect significant for consumer purchasing decisions on shampoo products registered Rejoice on the community Rantauprapat. The population of this research is the people who make purchases on the shampoo products registered Rejoice, samples in this research is 98 respondents. The results of the study showed that: 1) The prices have positive and significant impact on the consumer purchasing decisions on shampoo products registered Rejoice on the community Rantauprapat, and product quality have positive and significant impact on the consumer purchasing decisions on shampoo products registered Rejoice on the community Rantauprapat.
\end{abstract}

Key word : Price, Product Quality, Purchase Decision

\section{PENDAHULUAN}

Sebuah produk biasanya diluncurkan dengan tujuan bisa dikenal oleh masyarakat dan juga untuk menginformasikan apa yang ada di dalam produk itu sendiri. Diperlukan adanya bauran promosi yang tepat dan sesuai untuk meluncurkan sebuah produk supaya terjadi

keefektifan dan keefisienan agar masyarakat atau konsumen mau memutuskan untuk membeli produk tersebut.

Salah satu bauran promosi yang saat ini sedang marak-maraknya dilakukan para produsen adalah media periklanan. Berbagai jenis produk dan jasa dari bermacam-macam kategori menggunakan media periklanan sebagai alat untuk menyampaikan informasi kepada masyarakat dan konsumen. Adapun beberapa media periklanan yang bisa digunakan perusahaan seperti periklanan televisi, radio, telepon, internet, koran ,majalah, reklame luar ruang, dan brosur. Untuk bertahan hidup, berkembang dan dapat bersaing maka perusahaan harus mampu menjaga tingkat kepuasan konsumennya. Berbagai cara untuk menjaga kepuasan konsumen, salah satunya adalah dengan selalu meningkatkan kualitas produk yang dijual, dan selalu memperhatikan dan sebisa mungkin tidak menaikkan harga produk yang dijual.

Keputusan pembelian merupakan seleksi terhadap dua pilihan alternatif atau lebih konsumen pada pembelian. Setiap hari konsumen mengambil berbagai keputusan mengenai setiap aspek kehidupan sehari-hari. Tetapi, kadang mengambilkeputusaninitanpa memikirkan bagaimanamengambil

keputusan dan apa yang terlibat dalam proses pengambilan keputusan ini. Pilihan alternatif harus tersedia bagi seseorang ketika mengambil keputusan. Jika konsumen mempunyai pilihan antara melakukan pembelian dan tidak melakukan pembelian atau pilihan menggunakan waktu, maka konsumen tersebut berada dalam posisi untuk mengambil keputusan. 
Sebaliknya, jika konsumen tidak mempunyai alternatif untuk memilih dan benar-benar terpaksa melakukan pembelian tertentu atau mengambil tindakan tertentu, maka keadaan satu-satunya tanpa pilihan lain ini bukanlah suatu keputusan.

Keputusan konsumen untuk memodifik 102 sangat dipengaruhi oleh resiko yang terpikir Inda atau menghindari keputusan pembelian rnya resiko yang dipikirkan berbeda-beda menurut besarnya uang yang dipertaruhkan, besarnya ketidakpastian atribut, dan besarnya kepercayaan diri konsumen.

Berdasarkan uraian diatas meka peneliti tertarik untuk mengangakat permasalahan harga dan kualitas produk kedalam suatu penelitian dengan judul Pengaruh harga dan kualitas produk terhadap keputusan pembelian konsumen pada shampo merek Rejoice pada masyarakat Rantauprapat. Tinjauan Pustaka

\section{Harga}

Menurut Kotler \& Amstrong (2009:105:) harga merupakan sejumlah uang yang dibebankan atas suatu produk atau jasa atau jumlah dari nilai yang ditukar konsumen atas manfaat-manfaat karena memiliki atau menggunakan produk atau jasa tersebut. Sedangkan menurut Stanton (2007:98) harga pasar sebuah produk mempengaruhi upah, sewa, bunga, dan laba. Artinya, harga produk mempengaruhi biaya faktor-faktor produksi (tenaga kerja, tanah, modal, dan kewiraswastaan. Sehingga definisi harga adalah alat pengukur dasar sebuah sistem ekonomi karena harga mempengaruhi alokasi faktor-faktor produksi. Dan harga juga dapat didefinisikan sebagai jumlah uang yang dibutuhkan untuk memperoleh beberapa kombinasi sebuah produk dan pelayanan yang menyertainya.

FandyTjiptono(2009:89) mengemukakan harga sering kali digunakan sebagai indikator nilai bilamana indikator tersebut dihubungkan dengan manfaat yang dirasakan atas suatu barang atau jasa. Dengan demikian dapat disimpulkan bahwa pada tingkat harga tertentu, bila manfaat yang dirasakan konsumen meningkat, maka nilainya akan meningkat pula.

\section{Kualitas Produk}

Menurut Kottler dan Amstrong ( 2007 ) kualitas adalah karakteristik dari produk dalam kemampuan untuk memenuhi kebutuhan - kebutuhan yang telah ditentukan dan bersifat laten. Sedangkan produk adalah segala sesuatu yang dapat ditawarkan kepasar untuk mendapatkan perhatian, dibeli, digunakan, atau dikonsumsi yang dapat memuaskan keinginan atau kebutuhan. Secara konseptual produk adalah pemahaman subyektif dari produsen atas sesuatu yang bisa ditawarkan sebagai usaha untuk mencapai tujuan organisasi melalui pemenuhan kebutuhan dan kegiatan konsumen, sesuai dengan kompetensi dan kapasitas organisasi serta daya beli pasar. Selain itu produk dapat pula didefinisikan sebagai persepsi konsumen yang dijabarkan oleh produsen melalui hasil produksinya. Produk dipandang penting oleh konsumen dan dijadikan dasar pengambilan keputusan. Standarisasi kualitas sangat diperlukan untuk mencapai kualitas produk yang diinginkan. Cara ini dimaksudkan untuk menjaga agar produk yang diciptakan menghasilkan standar yang telah ditetapkan sehingga konsumen tidak akan kehilangan kepercayaan terhadap produk yang bersangkutan. Pemasar yang tidak memperhatikan kualitas produk yang ditawarkan akan menanggung tidak loyalnya konsumen sehingag penjualan produknya pun akan cenderung menurun.

\section{Keputusan Pembelian}

Keputusan pembelian merupakan kegiatan individu yang secara langsung terlibat dalam pengambilan keputusan untuk melakukan pembelian terhadap produk yang ditawarkan oleh penjual. Pengertian keputusan pembelian, menurut Kotler \& Armstrong (2007:90) dalam Ghazali (2010:88) adalah tahap dalam proses pengambilan keputusan pembeli di mana konsumen benarbenar membeli. 
Menurut Pamujo (2011:33) dalam keputusan membeli barang konsumen seringkali ada lebih dari dua pihak yang terlibat dalam proses pertukaran atau pembeliannya. Umumnya ada lima macam peranan yang dapat dilakukan seseorang. Kelima peran tersebut meliputi (Pamujo, 2011:33):

1. Pemrakarsa (initiator), yaitu orang yang $\mathrm{p}$

103 yang belum terpenuhi dan mengusulkan ide untuk membeli suatu barang atau jasa tertentu.

2. Pemberi pengaruh (influence), yaitu orang yang pandangan, nasihat atau pendapatnya mempengaruhi keputusan pembelian.

3. Pengambil keputusan (decider), yaitu orang yang menentukan keputusan pembelian.

4. Pembeli (buyer), yakni orang yang melakukan pembelian aktual.

5. Pemakai (user), yaitu orang yang menggunakan atau mengkonsumsi barang atau jasa yang dibeli

\section{METODE PENELITIAN}

Menurut Sugiyono (2012:100) populasi adalah wilayah generalisasi yang terdiri atas objek atau subjek yang mempunyai kualitas dan karakteristik tertentu yang ditetapkan oleh peneliti untuk dipelajari kemudian ditarik kesimpulan. Pada penelitian ini populasinya adalah masyarakat Kelurahan Perdamean.

Menurut Sugiyono (2012:100), sampel adalah bagian dari jumlah dan karakteristik yang dimiliki oleh populasi tersebut. Penentuan jumlah sampel ditentukan dengan menggunakan beberapa metode antara lain dengan menggunakan rumus sebagai berikut Widiyanto (2008:120).

$l .=4()^{2}$
$n=$

$8,01=98$ Dimana :

$n:$ Jumlah sampel

$\mathrm{Z}$ : Tingkat keyakinan yang dibutuhkan dalam penentuan sampel $95 \%$ pada penentuan ini $\mathrm{Z}$ pada $\alpha=0,5$ adalah 1,98 Moe : Margin of Error, yaitu tingkat kesalahan maksimal yang dapat ditoreransi, ditentukan sebesar 10\% Dari hasil perhitungan sampel diatas maka jumlah sampel dalam penelitian ini sebanyak 98 responden. Data primer adalah data yang diambil langsung dari tempat dimana penelitian dilakukan berupa wawancara kepada masyarakat serta jawaban responden terhadap kuisioner yang berhubungan dengan penelitian.

\section{HASIL PENELITIAN}

a. Analisis Regresi Linier berganda Metode statistik yang digunakan untuk menguji hipotesis adalah regresi linier berganda dengan bantuan perangkat lunak SPSS. Metode yang menghubungkan satu variabel dependen dengan variabel independen, sesuai hipotesis yang diuji dalam penelitian. Tabel berikut ini akan memperlihatkan hasil dari perhitungan untuk analisis regresi linier berganda dari $\mathbf{9 8}$ responden

Tabel 1. Regresi Linier Berganda

\begin{tabular}{|c|c|c|c|c|c|c|}
\hline \multicolumn{7}{|c|}{ Coefficients $^{\mathrm{a}}$} \\
\hline \multirow{2}{*}{\multicolumn{2}{|c|}{ Model }} & \multicolumn{2}{|c|}{$\begin{array}{c}\text { Unstandardized } \\
\text { Coefficients }\end{array}$} & \multirow{2}{*}{$\begin{array}{c}\text { Standardized } \\
\text { Coefficients } \\
\text { Beta } \\
\end{array}$} & \multirow[b]{2}{*}{$\mathrm{T}$} & \multirow[b]{2}{*}{ Sig. } \\
\hline & & $\mathrm{B}$ & Std. Error & & & \\
\hline & (Constant) & 10,525 & 2,860 & & 3,680 &, 000 \\
\hline & Harga & ,238 & ,084 & ,282 & 2,845 & ,000 \\
\hline
\end{tabular}




\begin{tabular}{|l|r|r|r|r|r|}
$\begin{array}{l}\text { Kualitas } \\
\text { produk }\end{array}$ &, 281 &, 137 &, 203 & 2,048 &, 000 \\
\hline
\end{tabular}

a. Dependent Variable: Keputusan pembelian

Dari hasil perhitungan diatas dapat dibuat sebuah model persamaan regresi linier berganda, yaitu sebagai berikut : Y $=10,525+104$

Persamaan regresi berganda tersebut $\mathrm{d}$ $1+0,281 \mathrm{X}_{2}$ sebagai berikut:

5. Nilai konstanta 10,525 memberi arti bahwa apaula harga $\left(\mathrm{X}_{1}\right)$, dan kualitas produk $\left(\mathrm{X}_{2}\right)$ sama-sama tetap pada nilai nol, maka keputusan pembelian (Y) yang dihasilkan bernilai 10,525.

6. Hargaberpengaruhpositifdan

signifikan terhadap keputusan pembelian dengan koefisien regresi sebesar 0,238. Artinya apabila harga naik 0,238 maka keputusan pembelian juga akan naik sebesar 0,238.

Kualitas produk berpengaruh positif dan signifikan terhadap keputusan pembelian dengan koefisien regresi sebesar 0,281. Artinya apabila kualitas produk naik 0,281 maka keputusan pembelian juga akan naik sebesar 0,281 .

\section{Uji Validitas}

Menurut sugiono (2012:89), instrumen yang valid berarti alat ukur yang digunakan untuk mendapatkan data (mengukur) itu valid. valid berarti instrumen tersebut dapat digunakan untuk mengukur apa yang seharusnya diukur dan data-data yang diperoleh dengan mengunakan instrumen dapat menjawab suatu penelitian. Uji validitas digunakan untuk mengukur sah atau valid tidaknya suatu kuesioner. Uji validitas dilakukan dengan membandingkan nilai $\mathrm{r}$ hitung dengan $\mathrm{r}$ tabel. Jika $\mathrm{r}$ hitung yang merupakan nilaicorrected item - total correlation $=\mathrm{r}$ tabelmaka alat ukur yang digunakan dinyatakan valid dan sebaliknya, jika $r$ hitung < r tabel maka alat ukur yang digunakan tidak valid. Nilai $r$ tabel diperoleh dengan persamaan N-2 = 98-3 = 95 (lihat tabel $\mathrm{r}$ dengSan df 95)=0,202. Nilai $\mathrm{r}$ hitung dalam uji ini adalah pearson Correlation antara item dengan skor pertanyaan. Diketahui untuk nilai dalam penelitian ini adalah sebesar $r$ hitung lebih besar dari $r$ tabel $(0,202)$. Artinya adalah seluruh item pernyataan dinyatakan valid.

Tabel 2

\begin{tabular}{|l|l|l|l|l|}
\hline \multirow{4}{*}{ Dimensi } & Indikator & R hitung & $\begin{array}{l}\mathrm{R} \\
\text { tabel }\end{array}$ & Kesimpulan \\
\hline \multirow{5}{*}{ Harga } & Item 1 & 0,536 & 0,202 & Valid \\
\cline { 2 - 5 } & Item 2 & 0,545 & 0,202 & Valid \\
\cline { 2 - 5 } & Item 3 & 0,560 & 0,202 & Valid \\
\cline { 2 - 5 } & Item 4 & 0,545 & 0,202 & Valid \\
\cline { 2 - 5 } & Item 5 & 0,560 & 0,202 & Valid \\
\hline \multirow{5}{*}{ Kualitas produk } & Item 1 & 0,515 & 0,202 & Valid \\
\cline { 2 - 5 } & Item 2 & 0,479 & 0,202 & Valid \\
\cline { 2 - 5 } & Item 3 & 0,571 & 0,202 & Valid \\
\cline { 2 - 5 } & Item 4 & 0,521 & 0,202 & Valid \\
\cline { 2 - 5 } & Item 5 & 0,529 & 0,202 & Valid \\
\hline \multirow{5}{*}{ Keputusan pembelian } & Item 1 & 0,447 & 0,202 & Valid \\
\cline { 2 - 5 } & Item 2 & 0423 & 0,202 & Valid \\
\cline { 2 - 5 } & Item 3 & 0,423 & 0,202 & Valid \\
\cline { 2 - 5 } & Item 4 & 0,427 & 0,202 & Valid \\
\cline { 2 - 5 } & Item 5 & 0,414 & 0,202 & Valid \\
\hline
\end{tabular}


Sumber: Data primer;2017

Dari tabel pengujian validitas dengan menggunakan SPSS diatas dapat dilihat bahwa semua item pernyataan pada variabel harga $\left(\mathrm{X}_{1}\right), \mathrm{k} l 105 \quad$ Juk $\left(\mathrm{X}_{2}\right)$ dan keputusan pembelian $(\mathrm{Y})$ memiliki nilai corrected item total correlation atau $\mathrm{r}$ munu ıuih besar dari $\mathrm{r}$ tabel sebesar 0,202 yang artinya dari masing- masing 5 item pernyataan pada variabel harga $\left(\mathrm{X}_{1}\right)$, kualitas produk $\left(\mathrm{X}_{2}\right)$ dan keputusan pembelian (Y) dinyatakan valid dan layak digunakan.

yang berjumlah 98 responden. Uji reliabilitas dilakukan pada butir-butir pernyataan yang telah valid. Teknik untuk menguji reliabilitas instrument yaitu dengan menggunakan metode cronbach'salpha dimana variabel tersebut akandinyatakan reliable dengan ketentuan Apabila nilainya kurang dari 0,6 adalah

kurang baik

6. Apabila nilainya 0,7 dapat diterima

7. Apabila nilainya diatas 0,8 adalah baik

Adapun hasil uji reliabilitas terhadap 98 responden dapat dilihat pada tabel berikut

\section{Uji Reabilitas} ini :

Selain uji validitas, dilakukan juga uji

reliabilitas kepada keseluruhan sampel

Tabel 3

\begin{tabular}{|l|c|c|c|}
\hline Indikator & $\begin{array}{l}\text { Cronbach's } \\
\text { Alpha }\end{array}$ & Nilai kritis & Kesimpulan \\
\hline Harga & 0,712 & 0,6 & Reliabel \\
\hline Kualitas produk & 0,685 & 0,6 & Reliabel \\
\hline Keputusan pembelian & 0,780 & 0,6 & Reliabel \\
\hline
\end{tabular}

Sumber: Data Olahan SPSS, 2017

Pada tabel diatas terlihat bahwa variabel harga $\left(\mathrm{X}_{1}\right)$, kualitas produk $\left(\mathrm{X}_{2}\right)$ dan keputusan pembelian (Y) memiliki nilai cronbach's alpha diatas 0,6 . Untuk variabel harga $\left(\mathrm{X}_{1}\right)$ nilai cronbach's alpha sebesar 0,712, kualitas produk ( $\left.\mathrm{X}_{2}\right)$ nilai cronbach's alpha sebesar 0,685, sedangkan untuk keputusan pembelian (Y) nilai cronbach's alpha sebesar 0,780. Hal ini bahwa variabel X dan Y tersebut telah memenuhi kriteria nilai batas dan dapat dinyatakan reliable serta layak untuk disebarkan kepada responden guna penelitian.

\section{c. Pengujian Hipotesis Koefisien Regresi Koefisien Determinasi}

Koefisien determinasi $\left(\mathrm{R}^{2}\right)$ adalah sebuah koefisien yang menunjukkan persentase pengaruh semua variabel independen terhadap variabel dependen. Persentase tersebut menunjukkan seberapa besar variabel independen (harga dan kualitas produk) dapat menjelaskan variabel dependennya (keputusan pembelian). Semakin besar koefisien determinasinya, semakin baik variabel dependen dalam menjelaskan variabel independennya. Dengan demikian persamaan regresi yang dihasilkan baik untuk mengestimasi nilai variabel dependen.

Untuk mengetahui besarnya pengaruh variabel independen dapat dilihat pada tabel berikut ini: 


\begin{tabular}{|l|r|r|r|}
\hline Model & \multicolumn{1}{|c|}{$\mathrm{R}$} & R Square & \multicolumn{1}{c|}{$\begin{array}{c}\text { Adjusted R } \\
\text { Square }\end{array}$} \\
\hline 1 &, $490^{\mathrm{a}}$ &, 553 &, 133 \\
\hline
\end{tabular}

a. Predictors: (Constant), Kualitas produk, Harga

b. Dependent Variablı 106 san pembelian

Berdasarkan hasil perhitungan di 106 ai koefisien determinasi sebesar 0,553. Artin

$55,3 \%$ variabel terikat dijelaskan oleh variabıe bebas dan sisanya dijelaskan oleh variabel lain diluar variabel yang digunakan. Dengan demikian model regresi linier berganda ini layak dipakai dalam penellitian, karena sebagian besar variabel terikat dijelaskan oleh variabel-variabel bebas yang digunakan dalam model.

\section{Uji Signifikan Individu (Uji t)}

Uji t dilakukan untuk mengetahui masing-masing variabel bebas terhadap variabel terikat secara parsial atau individual.Untuk menjawab hipotesis yang telahdiajukan, maka dilakukan uji t. Adapun rumus hipotesis statistiknya :

Ho : harga $\left(\mathrm{X}_{1}\right)$ dan kualitas produk $\left(\mathrm{X}_{2}\right)$ tidak ada hubungan dengan keputusan pembelian Ha : harga $\left(\mathrm{X}_{1}\right)$ dan kualitas produk $\left(\mathrm{X}_{2}\right)$ ada hubungan dengan keputusan pembelian Dengan kriteria pengujian :

7. Jika thitung < t tabel maka Ho diterima dan Ha ditolak

8. Jika thitung $>\mathrm{t}$ tabel maka Ho ditolak dan Ha diterima

Uji t dilakukan dengan membandingkan $t$ hitung dengan tabel padataraf signifikan $0,05 / 2=0.025$ dengan derajat kebebasan $\mathrm{T}$ tabel $=\mathrm{n}-\mathrm{k}-1:$ alpha/ $2=98-3-1: 0,05 / 2=94: 0,025=1,989$

Keterangan : $\mathrm{n}$ : jumlah, $\mathrm{K}$ : jumlah

variabel bebas, 1 : konstan

Hasil perhitungan diperoleh nilai t hitung $(2,845)>$ dari t tabel $(1,989)$ maka Ho ditolak dan Ha diterima, sehingga variabel

harga berpengaruh secara signifikan terhadap keputusan pembelian shampo merek Rejoice.

Hasil perhitungan diperoleh nilai t hitung $(2,048)>$ dari t tabel $(1,989)$ maka Ho ditolak dan Ha diterima, sehingga variabel

kualitas produk berpengaruh secara signifikan terhadap keputusan pembelian shampo merek Rejoice.

\section{Uji serentak (uji F)}

Tabel 5

Uji F

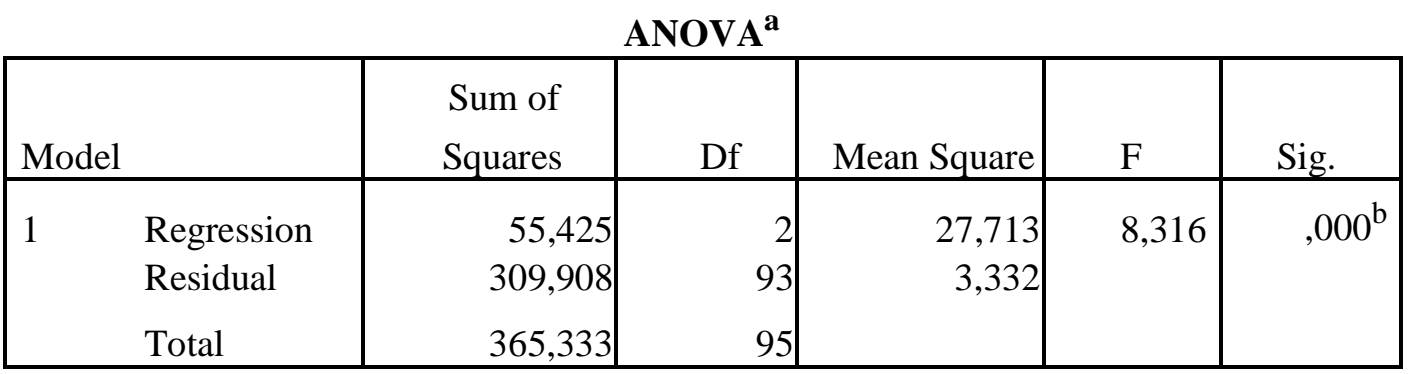

a. Dependent Variable: Keputusan pembelian

b. Predictors: (Constant), Kualitas produk, Harga 
Nilai F hitung $(8,316)>$ dari nilai $F$ tabel $(2,70)$ dengan nilai signifikan $0,000<0,05$ maka Ho ditolak sehingga ada pengaruh yang signifikan harga dan kualitas produk terhadap keputusan pembelian shampo merek Rejoice.

Kolmogorov Smirnov (Uji-KS) dan sebagai dasar penolakan atau penerimaan keputusan normal tidaknya distribusi data ditetapkan pada taraf signifikan alpha 0,05 .

a. Jika nilai sig atau signifikansi atau nilai probabilitas $(\mathrm{p})<0,05$ (taraf kepercayaan $95 \%$ ), distribusi adalah

\section{Uji Normalitas}

Uji normalitas merupakan persyaratan penting yang harus terpenuhi dalam analisis jalur, bila data yang dianalisis tidak berasal dari data yang berdistribusi normal, maka analisis regresi tidak terpenuhi. Pengujian normalitas data dilakukan dengan menggunakan teknik Uji tidak normal.

- Jika nilai sig atau signifikansi atau nilai probabilitas (p) > 0,05 (taraf kepercayaan $95 \%$ ), distribusi adalah normal

Adapun hasil pengolahan data untuk uji normalitas dapat dilihat pada Tabel berikut ini :

Tabel 6

Rangkuman Uji Normalitas Variabel Penelitian

\begin{tabular}{|l|l|l|l|l|}
\hline No & Variabel & Sig. Probability & Alpha & Keterangan \\
\hline 1 & Harga $\left(\mathrm{X}_{1}\right)$ & 0.576 & 0,05 & Normal \\
\hline 2 & Kualitas produk $\left(\mathrm{X}_{2}\right)$ & 0,746 & 0,05 & Normal \\
\hline 3 & Keputusan pembelian $(\mathrm{Y})$ & 0,865 & 0,05 & Normal \\
\hline
\end{tabular}

Dari Tabel 6 diketahui bahwa nilai signifikansi untuk variabel harga $\left(\mathrm{X}_{1}\right)$ sebesar 0.576, variabel kualitas produk $\left(\mathrm{X}_{2}\right)$ sebesar 0.746 , dan variabel keputusan pembelian (Y) adalah sebesar 0.865 . Jika nilai signifikansi dibandingkan dengan tingkat signifikan yang digunakan $(=0,05)$ maka terlihat bahwa nilai signifikan lebih besar. dari tingkat signifikan yang digunakan pada penelitian ini $(=0,05)$. 
Dengan demikian dapat disimpulkan bahwa semua variabel penelitian telah berdistribusi normal, dengan demikian analisis jalur dapat dilaksanakan karena data untuk semua variabel telah berdistribusi secara normal.

\section{Pembahasan}

Hasil pengujian koefisien harga terhadap keputusan pembelian memiliki jalur positif sebesar 0,238 yang berarti semakin baik harga akan semakin baik keputusan pembelian. Nilai probabilitas (p) sebesar 0,000 yang berarti ada pengaruh signifikan harga terhadap keputusan pembelian.

Hasil pengujian koefisien kualitas produk terhadap keputusan pembelian memiliki jalur positif sebesar 0,281 yang berarti semakin baik kualitas produk akan meningkatkan keputusan pembelian. Nilai probabilitas (p) sebesar 0,004 yang berarti ada pengaruh signifikan kualitas produk terhadap keputusan pembelian.

Variabel harga dan kualitas produk secara simultan berpengaruh signifikan terhadap keputusan pembelian konsumen pada produk shampo merek Rejoice yaitu sebesar 8,316. Besarnya pengaruh harga dan kualitas produk secara simultan berpengaruh signifikan terhadap keputusan pembelian konsumen pada produk shampo merek Rejoice sebesar 55,30\%. Sementara sisanya sebesar 44,70\% dipengaruhi oleh variabel lain yang tidak diteliti.

Dari persamaan regresi $\mathrm{Y}=10,525$

- 0,238 $\mathrm{X}_{1}+0,281 \mathrm{X}_{2}$ menunjukkan bahwa variabel kualitas produk lebih mempengaruhi keputusan pembelian konsumen pada produk shampo merek Rejoice.

\section{DAFTAR PUSTAKA}

Ghazali M. R., 2010. Analisis Pengaruh Lokasi, Promosi Dan Kualitas Layanan Terhadap Keputusan Membeli (Warnet Warung Internet) XYZ Jl.Singosari,

Kota Semarang). Fakultas Ekonomi UniversitasDiponegoro:

Semarang

Kotler, Philip Dan Kevin Lane Keller, 2007. Manajemen Pemasaran, Edisi

Keduabelas jilid kesatu. Indeks kelompok Gramedia: Jakarta Pamujo N. Yuga. 2011. Analisis PengaruhAtribut Produk, Bauran Promosi,Dan KualitasPelayananTerhadap Keputusan PembelianProduk Merchandise (Studi PadaKedai Digital 7 Di Semarang): skripsi. Fakultas Ekonomi Universitas Diponegoro: Semarang.

Santoso,S., 2007. SPSS StatistikMultivariat. Elex KomputindoKelompok Gramedia, Jakarta.

Sugiyono. 2012. Metode Penelitian Bisnis. Alfabeta: Bandung

Stanton, William J. 2007. Prinsip Pemasaran. Alih Bahasa oleh Sadu Sundaru. Jakarta : Erlangga.

Tjiptono,Fandy. 2009. StrategiPemasaran. Yogyakarta : Andi 